\title{
A Modified Control Scheme of Droop-Based Converters for Power Stability Analysis in Microgrids
}

\author{
Igor Usunariz,, ${ }^{1}$ Mikel Santamaria, ${ }^{2}$ Konstantina Mentesidi, ${ }^{2}$ and Monica Aguado ${ }^{2}$ \\ ${ }^{1}$ Department of Electrical and Electronic Engineering, Public University of Navarra, Arrosadia Campus, 31006 Pamplona, Spain \\ ${ }^{2}$ Renewable Energy Grid Integration Department, The National Renewable Energy Centre of Spain (CENER), \\ C/Ciudad de la Innovación 7, 31621 Sarriguren, Spain
}

Correspondence should be addressed to Konstantina Mentesidi; konstment@yahoo.gr

Received 18 June 2015; Revised 2 October 2015; Accepted 25 October 2015

Academic Editor: Sundaram Senthilarasu

Copyright (C) 2015 Igor Usunariz et al. This is an open access article distributed under the Creative Commons Attribution License, which permits unrestricted use, distribution, and reproduction in any medium, provided the original work is properly cited.

\begin{abstract}
Microgrid is principally an active distribution network since it aggregates numerous DG systems through their interface converters and different loads at distribution level. This paper discusses the power sharing in autonomous AC-microgrid infrastructure by common $P-f$ and $Q-\dot{V}$ droop control schemes on parallel-connected converters. Moreover, this research work proposes a frequency and voltage restoration mechanism through the utilization of secondary control. Experimental results are presented for a two$50 \mathrm{kVA}$ parallel-connected converter-based system, demonstrating the necessity for the proper operation of the secondary control in order to monitor the system's capability to withstand any perturbations that may occur and to ensure the system's security.
\end{abstract}

\section{Introduction}

In a conventional large electric power system, the central generators feed in the interconnected transmission system through their step-up transformers and the power being extracted from this high voltage network passes through a series of transformers to the distribution network to ultimately reach the clients' demand.

Lately, there has been an increasing interest towards the generation connection to the distribution network, the so-called distributed generation. The distributed generation concept refers to the small-scale generation that aims to minimize power losses as it is preferably allocated near the demand side.

In this context, the heart of distribution networks is portrayed by the "microgrid" concept since a microgrid can be defined as aggregation of loads and distributed generation such as micro generators operating like a single system, which provides both electrical and thermal energy [1].

Moreover, microgrid infrastructure generally groups renewable energy sources such as wind turbines, photovoltaic panels, conventional systems, that is, diesel generators and micro turbines, and various storage systems and loads.
Given that microgrids can be operated in two modes, (1) grid-connected and (2) stand-alone, voltage and frequency controls are essential for the proper operation of the system. The core of this research work focuses on the operation of a microgrid in islanded mode, since it is considered as the most complex one. Generally, there are several techniques to perform the voltage and frequency control in an autonomous power grid.

For instance, the systems based on a SMO (Single Master Operation) mode with a single Voltage Source Inverter (VSI) (the master that defines the frequency reference and the rest of the generation and/or storage systems running with $P / Q$ controls) are simple but not robust systems against network disturbances, and so forth. On the other hand, the Multimaster Operation (MMO) that allows for multiple inverters operated as VSI maintaining the reference values of voltage and frequency is a more complex but also a more robust operation mode [2].

Several configurations can be met in microgrids that work with the Multimaster droop control. Compound structures where storage systems operate under droop control and generators under $P / Q$ control mode, or even microgrids where all the generation and storage systems can operate under 
this control technique, all contribute to the maintenance and control of the grid.

This paper addresses the common $P-f$ and $Q-\dot{V}$ droop control techniques for two parallel-connected converters. Some novel modifications are proposed against common control loops developed in other publications, and the results of the simulations are shown, validating the technique used. In more detail, two additional terms, notably the voltage amplitude and the frequency derived from the secondary control, are used in order to maintain these values within their nominal rates at the Point of Common Coupling (PCC).

Figure 1 illustrates the microgrid infrastructure. The distributed energy resource (DER) units that were used for the tests include two battery converters $(50 \mathrm{~kW})$ with droop characteristics, a PV panel (50 kWp) interfaced to a threephase inverter, and a load bank $(60 \mathrm{~kW})$ consisting of a series of resistors and inductors. The battery converters are operating under MMO and are responsible for controlling the voltage and frequency values within specific limits for the appropriate performance of the autonomous power network.

This paper focuses on the MMO operation mode as the chosen microgrid control technique where the battery converters, through their developed control loops, will be responsible for managing the system in isolated mode and contributing to ancillary services in grid-connected mode. During isolated operation, the battery converters maintain the voltage and frequency limits within their predefined values through secondary control when the power network is subject to any fault incident, that is, connection and disconnection of large generation and load units, or even short ones. Furthermore, this research work discusses how the converters in grid-connected mode, apart from maintaining the voltage and frequency of the network, can also control the state of charge (SOC) of the storage systems and, more than that, the power set point of each microsource.

\section{Droop Control}

The power converter is granted as an ideal controllable source that it is connected to the main grid via line impedance, as depicted in Figure 2.

Thus, the active and reactive power components that the converter will yield to the grid can be written as [3-6]

$$
\begin{aligned}
P_{A} & =\frac{V_{A}}{R^{2}+X^{2}}\left[R\left(V_{A}-V_{B} \cos \delta\right)+X V_{B} \sin \delta\right], \\
Q_{A} & =\frac{V_{A}}{R^{2}+X^{2}}\left[-R V_{B} \sin \delta+X\left(V_{A}-V_{B} \cos \delta\right)\right],
\end{aligned}
$$

where $P_{A}$ and $Q_{A}$ are the active and reactive power components flowing from the converter to the grid ( $A$ to $B), V_{A}$ and $V_{B}$ are the voltage rates of these two sources, respectively, $\delta$ refers to the power angle, $Z=R+j X$ is the line impedance, and $\theta$ is the impedance angle.

Taking into account that the converter output impedance is considered to be inductive due to the high inductive component of the line impedance and the large inductor filter $(1 \mathrm{mH})$, we may assume that the line is mainly inductive $(X \gg$ $R)$; thus, the resistive part can be neglected [2]. In addition,

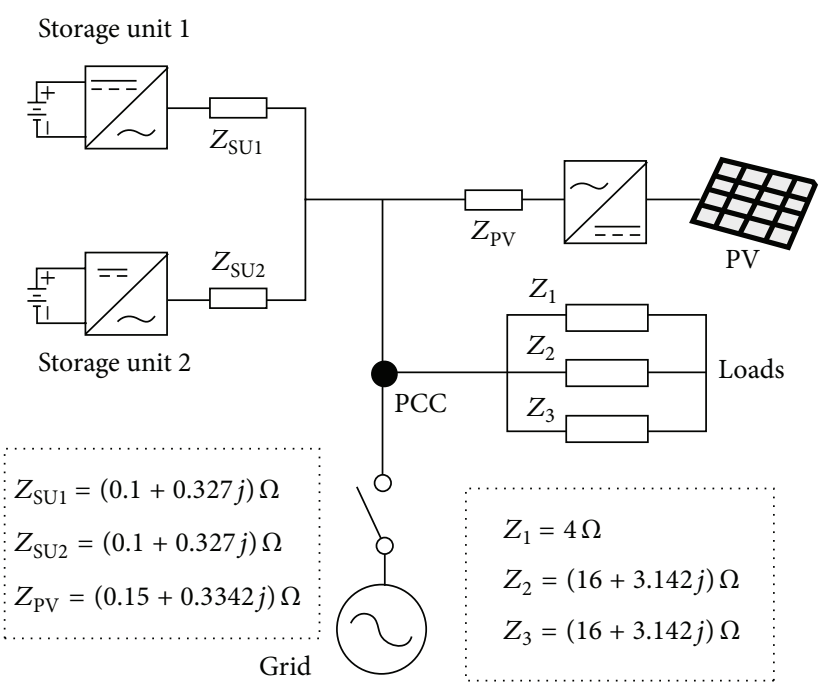

FIGURE 1: Microgrid topology.

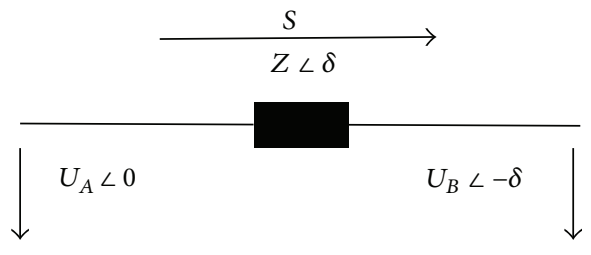

Figure 2: Power converter simplified circuit.

the power angle in such lines is small; thus, it can be regarded that $\sin (\delta) \approx \delta$ and $\cos (\delta) \approx 1$. Consequently, (1) can be rewritten as

$$
\begin{aligned}
P_{A} & \approx \frac{V_{A}^{2}}{X} \delta, \\
Q_{A} & \approx \frac{V_{A}\left(V_{A}-V_{B}\right)}{X}=\frac{V_{A} \Delta V}{X} .
\end{aligned}
$$

The expressions given by (2) and (3) under the hypothesis that the line is inductive address the notion that the active power $P$ is controlled by the power angle $\delta$, and the reactive power $Q$ is directly related to the difference of voltage amplitudes between nodes $A$ and $B$. This way to work imitates the operation of synchronous generators located in central power stations. Following this philosophy, the droop control equations are derived:

$$
\begin{aligned}
\omega & =\omega_{0}-m_{P}\left(P-P_{0}\right), \\
V & =V_{0}-n_{\mathrm{Q}}\left(Q-Q_{0}\right), \\
m_{P} & =\frac{\Delta \omega_{\max }}{P_{\max }}, \\
n_{\mathrm{Q}} & =\frac{\Delta V_{\max }}{Q_{\max }},
\end{aligned}
$$

where $V_{0}$ and $\omega_{0}$ illustrate the voltage and frequency idle values $(230 \mathrm{~V}$ and $50 \mathrm{~Hz}$ in this case) as shown in Figure 3, 


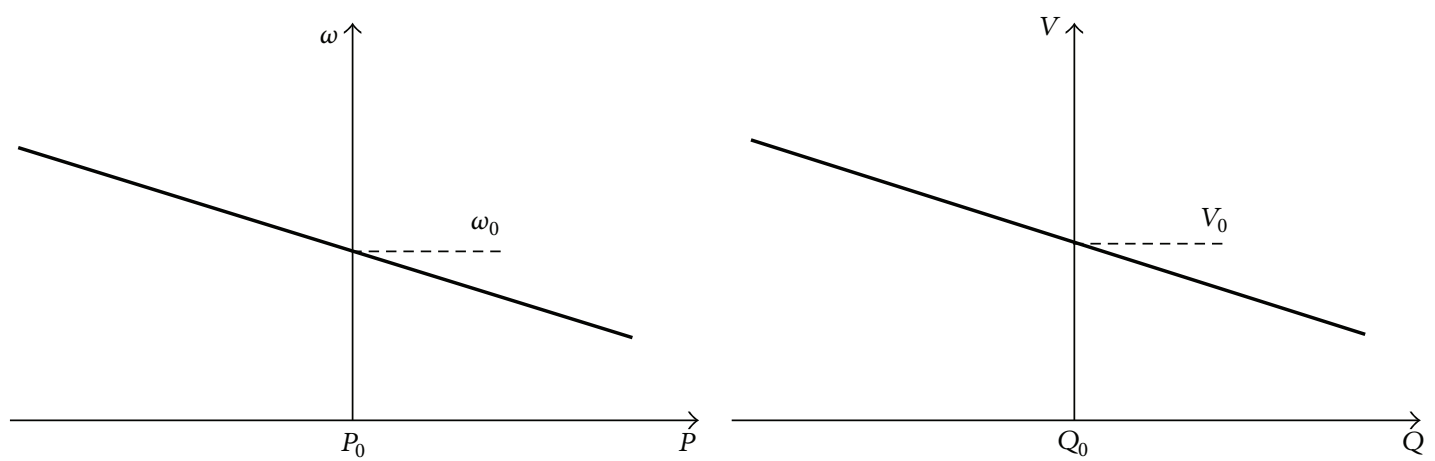

FIGURE 3: Droop characteristic curves.

$\Delta V_{\max }$ and $\Delta \omega_{\max }$ represent the maximum voltage and frequency deviations, respectively, and $P_{\max }$ and $Q_{\max }$ depict the maximum active and reactive power delivered by the converter.

This method, based on frequency and voltage deviations with respect to their nominal values, has a great advantage over others. For instance, by increasing the values of " $m_{p}$ " and " $n_{\mathrm{O}}$ " parameters, we can achieve better power sharing but lose voltage regulation. However, this loss may be acceptable if the frequency and voltage deviations are within permissible limits, which are explained later on in Section 4.1. The selection of the droop characteristic coefficients depends on the converters' electrical parameters, as it can be seen in (6) and (7).

However, the frequency and voltage deviations, as well as the limitations imposed by the converter's electrical parameters, restrict the range of droop coefficient values. This can be a significant barrier in terms of accuracy in power sharing, system stability, and transient response. In addition to these issues, when performing the droop expressions given in (4) and (5), it is vital to calculate the average values of instantaneous active and reactive power over one line cycle. This can be achieved by using a low pass filter that affects the system's dynamic behavior and is suitable for this calculation, that is, with a small cut-off frequency, since we want to achieve a delay by one cycle of the grid voltage. Taking into account the delay introduced by the filter, the droop equations are as follows [2]:

$$
\begin{aligned}
& \omega=\omega_{0}-m_{P} \frac{\omega_{\text {filter }}}{s+\omega_{\text {filter }}}\left(P-P_{0}\right), \\
& V=V_{0}-n_{Q} \frac{\omega_{\text {filter }}}{s+\omega_{\text {filter }}}\left(Q-Q_{0}\right) .
\end{aligned}
$$

In conclusion, the droop control method allows for good load sharing between converters. This is true for the case of the active power. However, $Q-V$ droop control on individual inverters suffers from the dependence on output line impedance. Inaccurate reactive power sharing will take place under considerably nonuniform line impedance, unless the characterization of line impedances is done in a very precise way. To solve these issues, modifications to conventional droop method are proposed and are analyzed within the next section.

\section{Conventional Droop Control Modification}

3.1. Secondary Control. The conventional droop control is based on provoking small deviations on frequency and voltage in order to control the power delivered by the converter. However, these deviations must be compensated in order to maintain the stability of the network. As already stated, the secondary control is responsible for restoring the values of frequency and voltage to their nominal levels $[3,6,7]$.

One great advantage of droop control over other controls is that it does not need internal communication between different converters connected in parallel to carry out proper sharing of power absorbed by the load. Each converter controls the delivered power taking into account the local parameters and the output measured values. In this way, the use of fast communication lines with a large bandwidth is avoided.

Nevertheless, the secondary control supervises the proper operation of the overall system, so that the signals sent by this control are common to all devices. This makes the existence of a communication line between devices necessary. Unlike conventional droop control, secondary control is much slower because it corrects the deviations caused by the droop controller scheme. Consequently, the communication lines necessary to carry out this control are slower and therefore can be done with a lower bandwidth. Moreover, the robustness and reliability of the system are not threatened. The secondary control consists of four PI controllers, one for frequency and three for voltage control for each phase that will be the additional terms in $P-f$ and $Q-\dot{V}$ droop controllers, respectively. This control only acts in islanded operation; otherwise, the power grid itself is responsible for performing frequency and voltage regulation with the assistance of the droop controllers. For instance, when a short circuit occurs, the voltage falls to few volts since the secondary control is incapable of correcting this voltage drop until this fault is cleared by the protections. Thus, the secondary control is annulled. The microgrid central unit is the one that detects the voltage drop and stops and resets the loop.

3.2. Derivative Term Addition to the P- $f$ Loop. The gain of the control action by which we obtain the steady-state response 


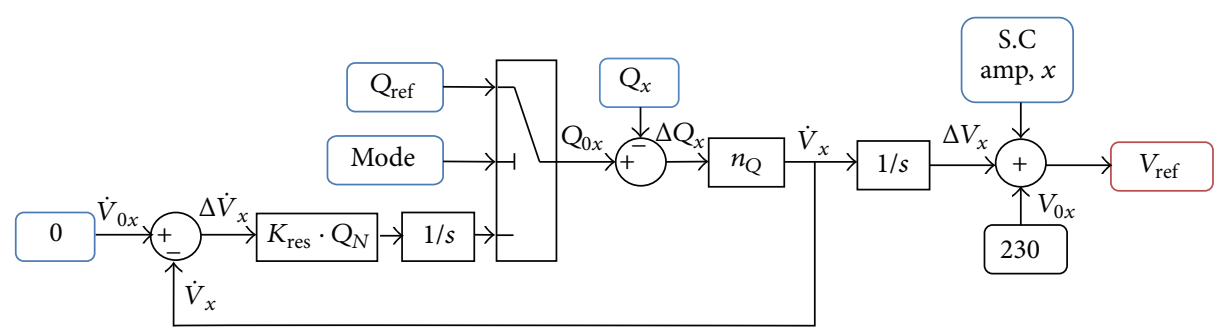

FIgURE 4: Modified $Q-\dot{V}$ droop controller.

consists of only one parameter to adjust. This means that it cannot simultaneously control the transient and steady response. In order to improve the transient response and eliminate the overshooting that may occur due to the droop control, a derivative term is introduced to anticipate such changes $[2,8]$. Thus, the improved $P$ - $f$ droop controller is given beneath, where $m_{P}$ and $m_{d}$ are the proportional and the derivative power coefficients:

$$
\omega=\omega_{0}-m_{P}\left(P-P_{0}\right)+m_{d} \frac{d P}{d t} .
$$

The suggested control method permits modifying separately the dynamic performance by adjusting the control coefficients and simultaneously keeping the steady-state values of frequency and voltage constant. Thus, it is possible to obtain the desired response for both transient and static regimes. It should be emphasized that although the conventional droop control is performed on the deviation between the reference and measured values of instantaneous active power, the newly introduced derivative control term is performed only on the measured active power. Thereby, it can moderate the variations that the latter may suffer from after changes in its reference input. Consequently, this term becomes practically zero at steady state to ensure constant frequency regulation by modifying the inverter frequency and at the same time reaching active power balance during load transients.

3.3. Modification of the Q-V Loop. As previously discussed, the reactive power sharing via the conventional droop control method has some shortcomings. Unless the determination of line parameters is very accurate, the power sharing is not done correctly and is degraded. This can result in an unbalance of reactive power flow for loads that are located closer to one converter than another despite both converters having the same droop coefficients.

To overcome this problem, the $Q-\dot{V}$ droop control scheme is proposed in $[9,10]$ for reactive power sharing among parallel-connected inverters where $\dot{V}$ is the rate of change of the voltage magnitude $(V)$. The equations governing this method are the ones below where $x$ represents each one of the three phases:

$$
\begin{aligned}
\dot{V}_{x} & =\dot{V}_{0 x}-n_{\mathrm{Q}}\left(Q_{0 x}-Q_{x}\right), \\
V_{\text {ref }} & =V_{0 x}+\int \dot{V}_{x} d t,
\end{aligned}
$$

TABLE 1: Droop controller gains.

\begin{tabular}{lc}
\hline$P-f$ & Values \\
\hline$m_{p}$ & $0.00012566(\mathrm{rad} / \mathrm{s} \omega)$ \\
$m_{d}$ & 0.0001 \\
\hline
\end{tabular}

TABLE 2: Droop controller gains.

\begin{tabular}{lc}
\hline$Q-\dot{V}$ & Values \\
\hline$n_{\mathrm{Q}}$ & $0.02(\mathrm{~V} / \mathrm{VARs})$ \\
$K_{\text {res }}$ & $0.05(1 / \mathrm{V})$ \\
\hline
\end{tabular}

TABLE 3: Voltage secondary controller gains.

\begin{tabular}{lc}
\hline & Values \\
\hline$K_{\mathrm{pv}}$ & 0.08 \\
$T_{\mathrm{nv}}$ & 0.0269 \\
\hline
\end{tabular}

where $\dot{V}_{0 x}$ is the nominal value of $\dot{V}_{x}$ that is decided to be $0 \mathrm{~V} / \mathrm{s}$ in order to avoid steady-state voltage variations; $n_{\mathrm{Q}}$ is the reactive power droop coefficient; $Q_{0 x}$ is the reference power delivered to the inverter; $Q_{x}$ is the instantaneous reactive power output of the inverter; and $V_{\text {ref }}$ is calculated by the droop that serves to generate the reference voltage and the nominal voltage $V_{0 x} ; V_{\text {rms }}$ value of $230 \mathrm{~V}$ is set here.

In grid-connected mode, once the power output has reached the reference value, the voltage remains stable and constant without variations until it receives a different set point value. On the contrary, when the system is isolated, it is necessary to introduce $\dot{V}$ restoration mechanism in order to reset the value to zero [9]. If that was not done, despite having a zero reference for the reactive power output, the converter will contribute with its reactive share that causes the error $\left(\Delta Q_{x}\right.$, Figure 4$)$ to never be zero and thus, after the integration of $\dot{V}$, a variation in voltage amplitude always exists and consequently the system becomes unstable. The restoration mechanism (Figure 4) involves adding an extra gain $K_{\text {res }} * Q_{N}$ (reactive power nominal value) to the $Q-\dot{V}$ control loop to eliminate the error between $\dot{V}_{0 x}$ and $\dot{V}_{x}$.

The droop and controller gains are given in Tables 1, 2, 3, and 4 .

In conclusion, we may distinguish two ways to deliver set points for the converter's reactive power. In grid-connected mode, the reactive power reference set point is sent externally, which is compared to the instantaneous measured value, and 


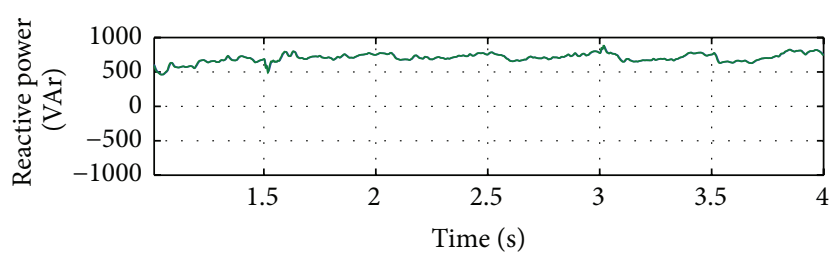

(a)

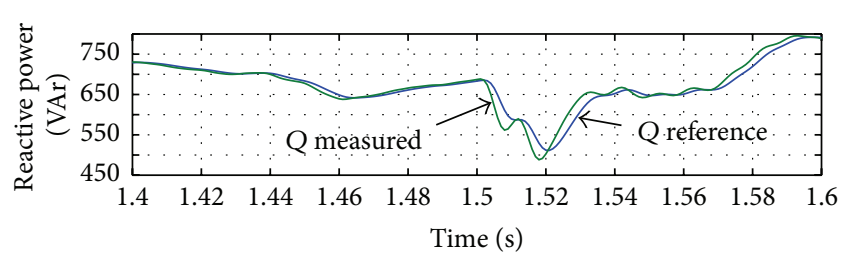

(b)

FIGURE 5: Behavior of reactive power in islanded operation.

TABLE 4: Frequency secondary controller gains.

\begin{tabular}{lc}
\hline & Values \\
\hline$K_{\mathrm{pf}}$ & 0.001 \\
$T_{\mathrm{nf}}$ & 0.02 \\
\hline
\end{tabular}

the appropriate actions are taken. On the other hand, operating in islanded mode, instead of comparing the input and output desired values, the reactive power set point is modified through the restoration mechanism loop, so this follows the output power delivered by each converter. Figure 5 depicts the aforementioned with the reference following the power output, rather than the reverse.

\subsection{Control by Means of P and Q Set Points in Grid-Connected} Mode. The droop control schemes that appear in the literature are used mainly for two functions depending on the operation mode. For instance, in autonomous systems, the parallel-connected inverters can operate as grid-forming with droop characteristics and achieve good active and reactive current sharing.

However, for grid-connected operation, the parallelconnected inverters regulate the grid voltage while maintaining the preset frequency and voltage levels. The only moment that active power is delivered is when the grid frequency falls, and once restored to its nominal value, the converter will deliver zero output power. The same applies to reactive power, when the voltage drops; thus the converter supplies reactive power until voltage reaches its preset value.

Modifying the idle values $\left(V_{0}, \omega_{0}\right)$ according to $P / f$ and $Q / V$ converters' droop characteristics, it is possible to regulate the output power delivered to the system. In case of battery interfaced converters, this strategy serves to charge and discharge the batteries.

Two adjustable parameters do only exist within the droop controllers. On the one hand, there are unmodified coefficients, because they are restricted by the electrical parameters of the converter and the idle values of its droop characteristics. By modifying these values, the active and reactive reference set points also change. For instance, a nonzero reference active power value is achieved by moving the point of intersection with the vertical axis from $\omega^{*}$ to $\omega$ by adding $\Delta \omega$ term, as shown in Figure 6. Since the network is operating at frequency $\omega^{*}$, this generates an error according to the droop equation that makes the generator operate at a frequency different from the network's one.

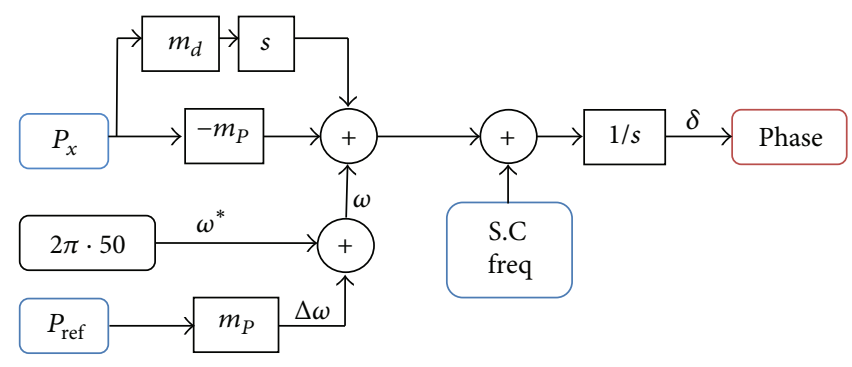

FIGURE 6: $P-f$ droop characteristic modification.

The result of the frequency error integration is the phase angle difference between the grid and the converter's output voltage $(\delta)$, which in turn also changes the output power since it is directly related to it (see (2)). Once it reaches the value of the reference power, the frequency error is canceled maintaining the voltage deviation and, hence, also the power constant.

\section{Simulation Platform}

4.1. Operation Limits. Due to the lack of existing standards and regulations regarding islanded networks in Spain, several limit settings have been adopted by different actors in the Spanish electricity system. Still, in the absence of established references, these values have been used throughout this work to have a comparative framework as a basis.

4.1.1. Frequency. Frequency is a single parameter for the entire network connected to European electricity system, so it must be controlled and maintained to a constant value, notably $50 \mathrm{~Hz}$. The secondary control is responsible for this function and resets the frequency to its nominal value after a fault incident occurrence.

Table 5 illustrates the permissible variations in frequency under different statutory limits that exist in the Spanish power network. According to UNESA [11], "the Spanish nominal system frequency is $50 \mathrm{~Hz}$. The frequency limits need to lie between 49.85 and $50.15 \mathrm{~Hz}$."

According to Union Fenosa's normative [12] which applies to systems connected to its distribution network, "the power plants are disconnected from the network when the frequency is outside the range of $48 / 51 \mathrm{~Hz}$ for a maximum time of 100 ms.” 
TABLE 5: Frequency limits.

\begin{tabular}{lcc}
\hline Events & Value $(\mathrm{Hz})$ & Time duration $(\mathrm{ms})$ \\
\hline Overfrequency & $50.15 / 51$ & $<100$ (Union Fenosa) \\
Nominal frequency & 50 & - \\
Underfrequency & $49.85 / 48$ & $<100$ (Union Fenosa) \\
\hline
\end{tabular}

TABLE 6: Voltage limits.

\begin{tabular}{lcc}
\hline Events & Value (p.u.) & Time duration $(\mathrm{ms})$ \\
\hline Overvoltage & 1.1 & $<500$ \\
Nominal voltage & 1 & - \\
Undervoltage & 0.85 & $<500$ \\
\hline
\end{tabular}

TABLE 7: Power ratings.

\begin{tabular}{lc}
\hline Devices & Power \\
\hline PV & $50 \mathrm{kWp}$ \\
Battery converters & $60 \mathrm{kVA}$ \\
Load $\left(Z_{1}\right)$ & $40 \mathrm{~kW}$ \\
Load $\left(Z_{2}\right)$ & $10 \mathrm{~kW}+50 \mathrm{kVAr}$ \\
Load $\left(Z_{3}\right)$ & $10 \mathrm{~kW}+50 \mathrm{kVAr}$ \\
\hline
\end{tabular}

4.1.2. Voltage. According to Union Fenosa normative [12], "the power system shall be disconnected from the Fenosa's distribution network when the nominal voltage $\left(U_{n}\right)$ is outside the range of $0.85 U_{n} / 1.1 U_{n}$, considering a maximum time of $500 \mathrm{~ms}$." Therefore, the secondary control should act before the voltage reaches levels out of the limits specified in Table 6.

\section{Experiments and Results}

In order to check the stability of the network generated by the droop converters and analyze whether this control method is suitable for isolated network systems, various events have been simulated. These are presumably the worst case scenarios that may affect the system's stability and are as follows: fluctuation of the photovoltaic inverter power output, three-phase fault applied to one of the load branches and subsequent disconnection of the affected line, and finally step load changes at different power levels.

All the scenarios checked over the network's stability. Moreover, the power balance between different converters was analyzed in order to verify the correct operation of the droop control, the network frequency, the rms voltage values that supply the loads, and the Total Harmonic Distortion (THD) of the output voltage. Furthermore, the system's response is also checked under secondary control in order to analyze its effectiveness and examine if it is feasible to solely control the system by means of the same. Table 7 concentrates the system's parameters.

5.1. PV Power Fluctuation. First of all, a measurement of the actual output current of a PV array rated at $50 \mathrm{kWp}$ was implemented to assess current variations against cloud shadow effect. Among these data, the most unfavorable one

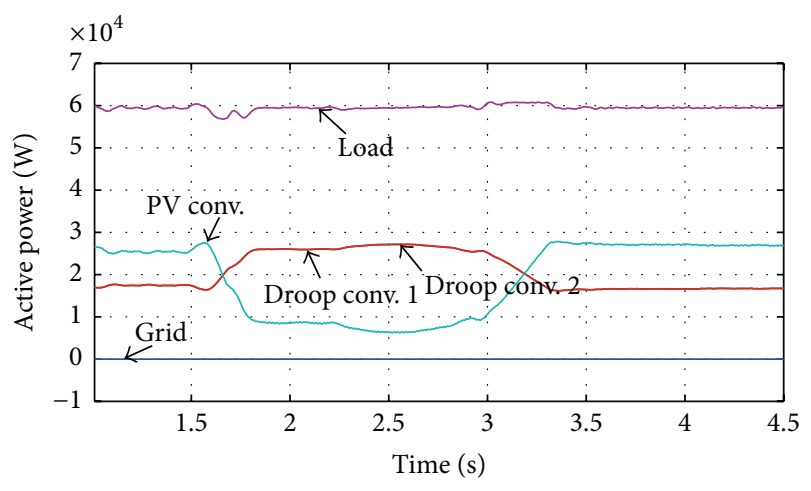

FIGURE 7: Active power balance and power sharing.

(high $d i / d t$ ) was introduced as input in the PV inverter to evaluate the transient response of the system to such current variations.

In Figure 7 , at $t=1.5 \mathrm{~s}$, the cloud effect causes a drop of $70 \%$ in the output power of the PV system, notably from $26 \mathrm{~kW}$ to $8 \mathrm{~kW}$. Prior to this event, the converters provide $17 \mathrm{~kW}$ each, necessary to balance the $60 \mathrm{~kW}$ load demand. Once the photovoltaic production has declined, each converter needs to produce more power and supply $26 \mathrm{~kW}$ in order to cover the demand. At $t=3 \mathrm{~s}$, the PV system production is restored and the system returns to its prefault state.

Figures 8 and 9 illustrate the results of the frequency and voltage responses. As it can be observed, when partial cloud effect occurs, the frequency of droop controlled converters decreases slightly. However, this decrease is compensated by the secondary control that restores the frequency to its nominal value. Besides, this control acts fast enough to not allow the frequency variations beyond the $\pm 0.3 \%$ range (Figure 8).

Similarly, the mean average of the rms values of the three-phase load voltages also drops due to the decrease in the power delivered by the photovoltaic inverter, and the secondary control will rapidly correct and restore the voltage to its nominal value. At the moment, the PV system returns to its prefault production, and the voltage rises again, but still the secondary control is responsible for keeping the average voltage within its permissible limits (Figure 9).

The THD of the output voltage is less than $1 \%$ at steadystate regime and ensures low harmonic injection into the system (Figure 10).

The experimental results depicted in Figures 7, 8, 9, and 10 evaluated the good performance of the proposed droop control scheme. In more detail, the tests performed showed that the system is able to absorb satisfactorily the power variations generated by the photovoltaic installation. Moreover, good power sharing for both active and reactive power among the two parallel-connected inverters when supplying a linear load was observed.

5.2. Three-Phase to Ground Fault Case. A short-circuit fault is one of the most critical events that can occur in a system. 


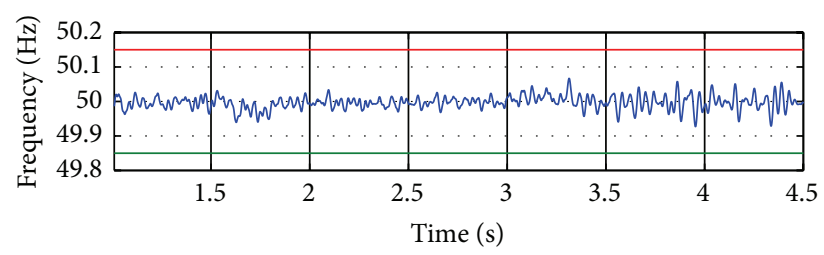

(a)

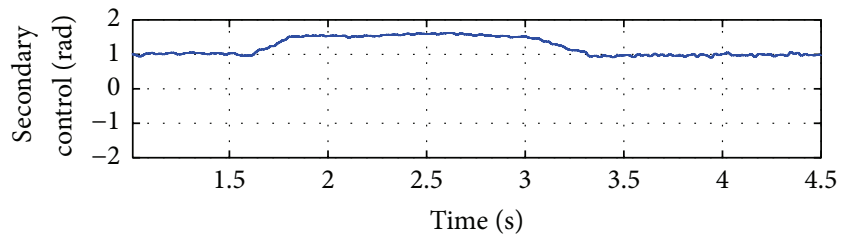

(b)

Figure 8: Frequency control. (a) Frequency at PCC. (b) Secondary control's response.

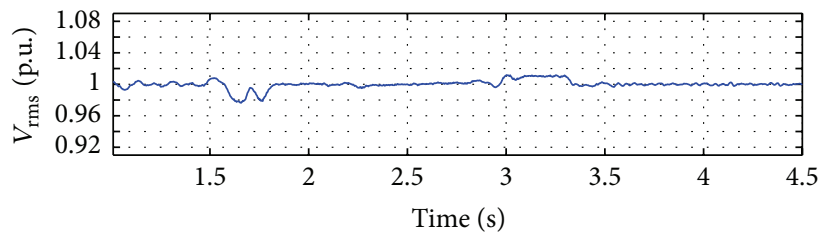

(a)

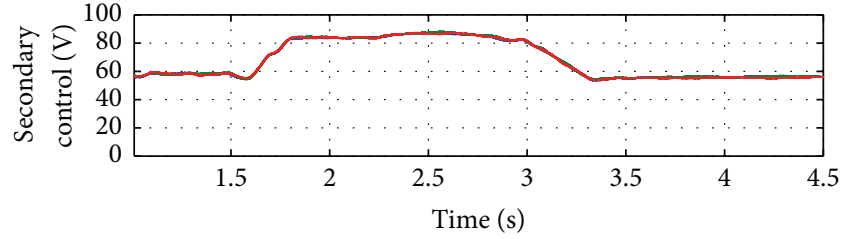

(b)

FIgURE 9: Voltage rms value control. (a) $V_{\text {rms }}$ at PCC. (b) Secondary control's response.

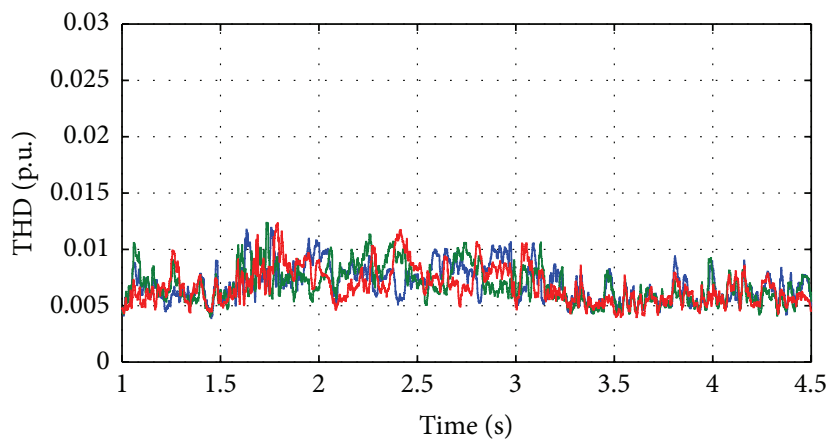

FIGURE 10: Instantaneous three-phase voltage fluctuation at PCC.

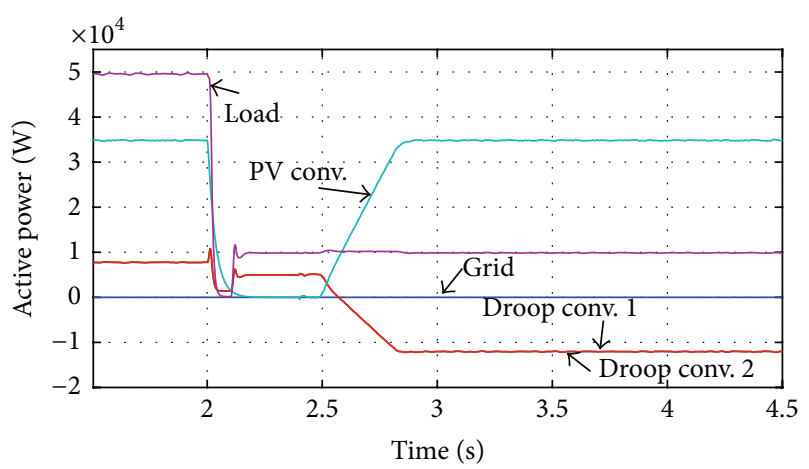

FIGURE 11: Active power balance and power sharing.

Among the most critical perturbations is a bolted three-phase fault application at a distribution line.

Before the short-circuit incident, the PV power production is rated at $34 \mathrm{~kW}$ and the battery converters generated $8 \mathrm{~kW}$ each in order to cover the load demand of $50 \mathrm{~kW}$ (Figure 11).
At $t=2 \mathrm{~s}$, a fault occurs on the branch loads of $40 \mathrm{~kW}\left(Z_{1}\right.$, Figure 1), which accounts for $80 \%$ of the total power of the loads connected to the system. After $100 \mathrm{~ms}$, the protections disconnect this line, and the system is restored with total load consumption of $10 \mathrm{~kW}$. In this new scenario, the two battery converters need to absorb $12 \mathrm{~kW}$ each, because there is excess in generation of $24 \mathrm{~kW}$ due to a reduction of $40 \mathrm{~kW}$ in load demand. During the short-circuit event, the photovoltaic inverter is disconnected because an undervoltage protection is utilised as required by the grid connection regulations for the Spanish power systems. Once it is assured that the system has been restored and has reached a steady-state regime, the PV system is reconnected.

During the fault incident, the frequency is maintained within acceptable values. Only a small oscillation occurs but the secondary control corrects it (Figure 12). Analyzing the evolution of the rms voltage (Figure 13) at the PCC, it is observed that, as soon as the protections are on, the voltage is restored and there is hardly any overshoot. The secondary control is annulled for $120 \mathrm{~ms}$ (during the shortcircuit event plus a delay of $20 \mathrm{~ms}$ ) in order to achieve very small voltage overshoot after the short circuit is cleared. Figure 13 illustrates the fault incident starting at about $2 \mathrm{~s}$ 


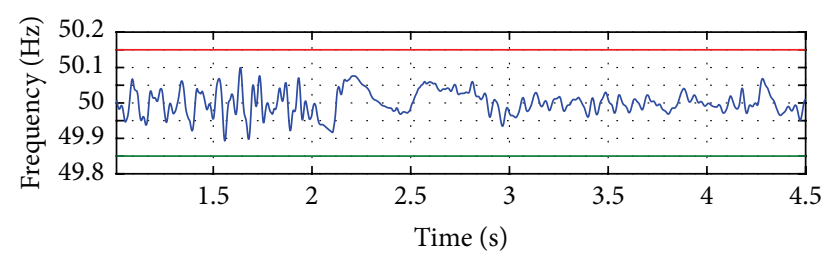

(a)

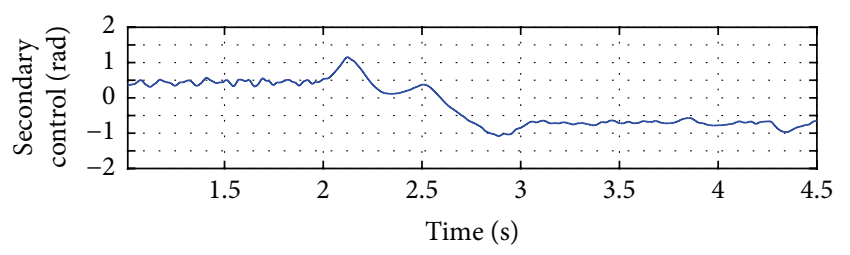

(b)

Figure 12: Frequency control. (a) Frequency at PCC. (b) Secondary control's response.

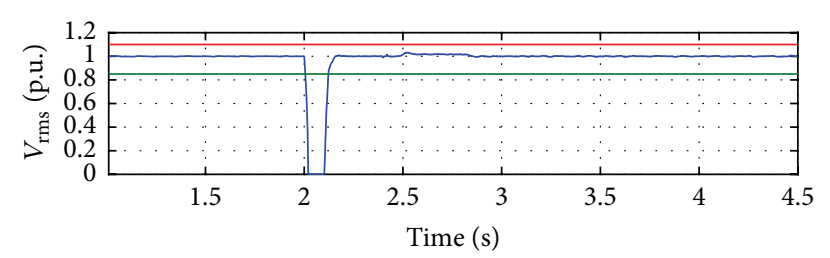

(a)

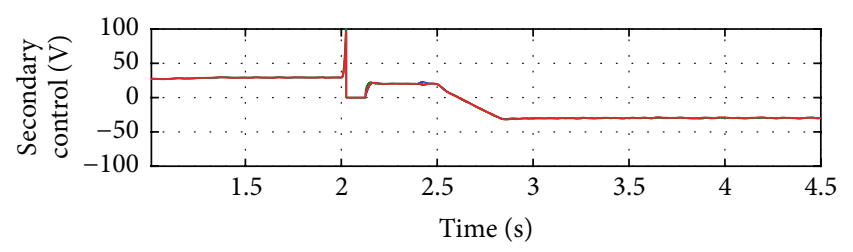

(b)

Figure 13: Voltage rms value control. (a) $V_{\text {rms }}$ at PCC. (b) Secondary control's response.

and that secondary control reaches saturation at the time short circuit is produced. The PI droop controller reboots the integral term and induces smooth voltage restoration by avoiding voltage overshoots (Figure 12).

5.3. Load Step Changes. From the grid point of view, the most favored condition of a microgrid is that it is treated as a controlled entity within the power system. Some management and operational issues related to microgrid infrastructure are as follows: (1) the system security should be sustained through contingency and emergency conditions, that is, load demand side management, load shedding, islanding, and closedown of power units and (2) momentary mismatch between generation and load should be mitigated via proper load forecasting and demand side management. For instance, if excessive consumption over instant generation occurs, less critical loads must be disconnected and be reconnected when possible.

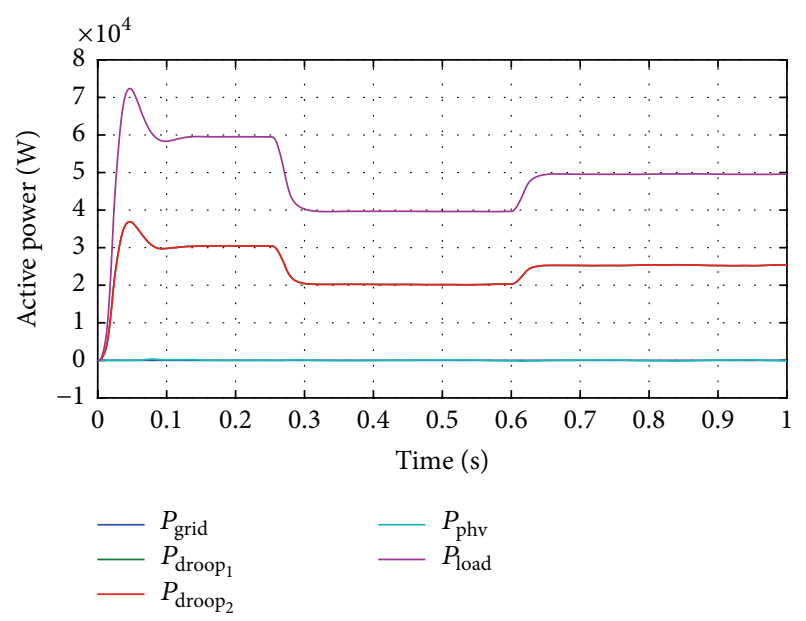

FIGURE 14: Power sharing with secondary control during step load change.

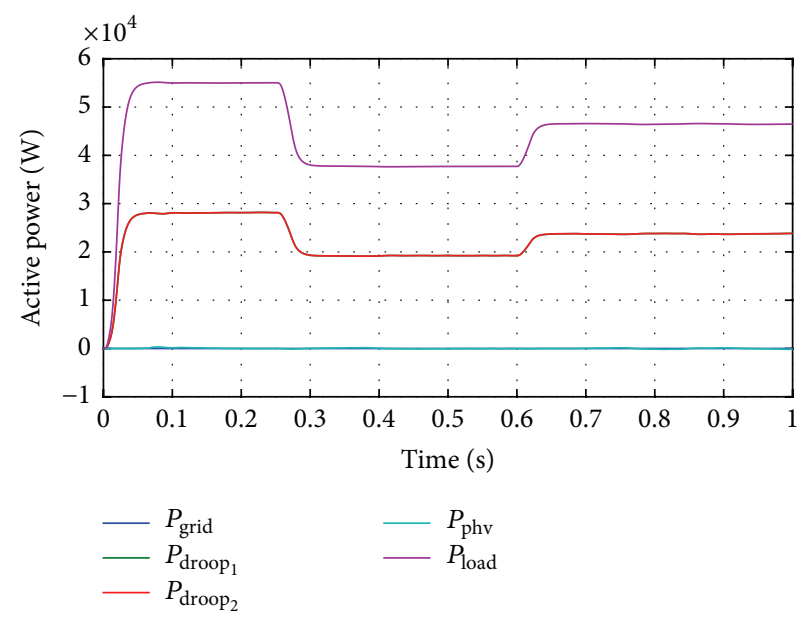

FIGURE 15: Active power sharing without secondary control during step load change.

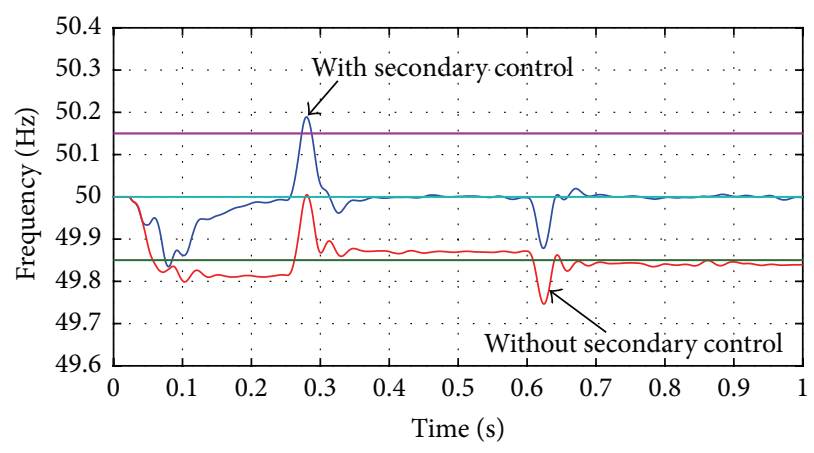

FIGURE 16: Frequency response with and without secondary control during step load change.

First of all, a step load change has been considered from $60 \mathrm{~kW}$ to $40 \mathrm{~kW}$ and then up to $50 \mathrm{~kW}$, as illustrated in Figures 14 and 15 with and without secondary control, respectively. When the secondary control is not taken into account, the rms voltage reaches its steady-state regime at a level that it is distinct from the one that the system should 


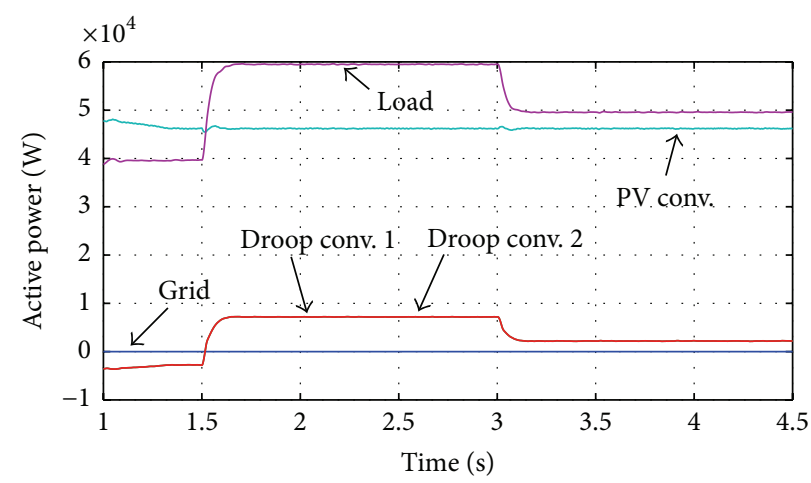

FIGURE 17: System dynamics under step changes in load.

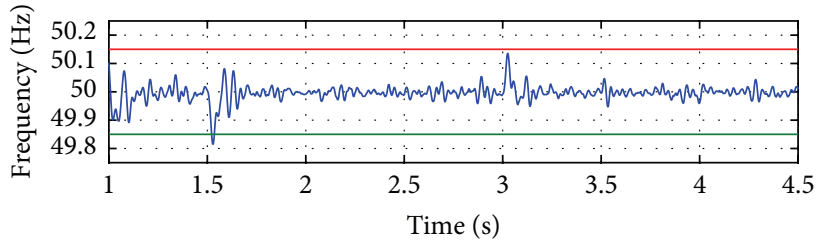

(a)

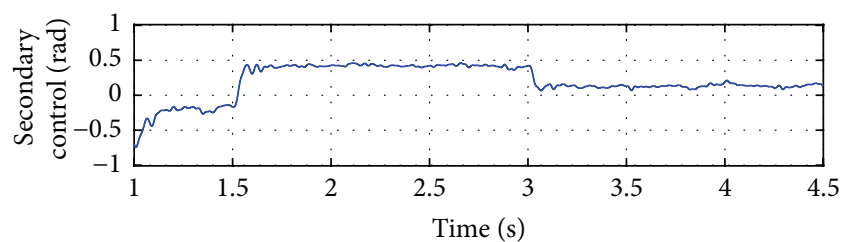

(b)

FIGURE 18: Frequency control. (a) Frequency at PCC. (b) Secondary control's response.

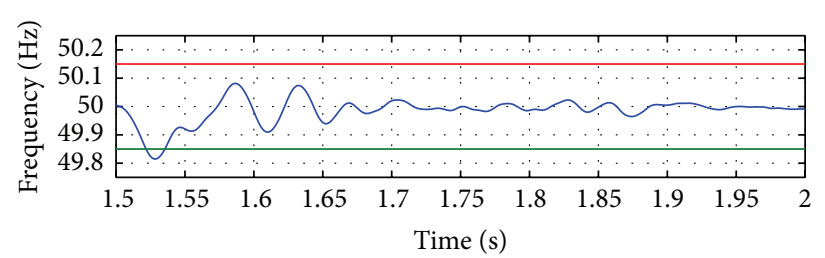

(a)

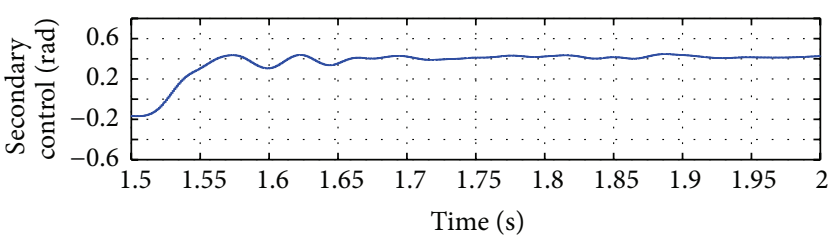

(b)

FIGURE 19: Frequency dynamic behaviour under step increase in load.

operate at, that is, 1 p.u., namely, $230 \mathrm{~V}$. In our case scenario (Figure 16), when the load demand is of 60,40 , and $50 \mathrm{~kW}$, the rms voltage will be $0.95,0.97$, and 0.96 p.u. accordingly.

As far as frequency is concerned, a similar situation occurs and it is depicted in Figure 17 when secondary control is not implemented. In more detail, when the load demand is of 60,40 , and $50 \mathrm{~kW}$, the frequency drops down to 49.81 , 49.87 , and $49.85 \mathrm{~Hz}$ accordingly.

Figures 18-20 illustrate the experimental results from the tests related to load step changes and static-loads' connection and disconnection. As it is explained beneath, the tested system can manage the load demand and hence keep the network parameters within acceptable values.

Figure 18 depicts good active power sharing between the two parallel-connected battery converters. In this case, there has been a load step at $t=1.5 \mathrm{~s}$, from $40 \mathrm{~kW}$ to $60 \mathrm{~kW}$ peak consumption. At $t=3 \mathrm{~s}, 10 \mathrm{~kW}$ of load consumption is disconnected. Nevertheless, when the demand exceeds the power generated by the PV system, the droop converters feed the loads with the required power and maintain the system security.
Figure 19 illustrates that, at the time of the load addition, frequency drops, even lower than its permitted limit. However, the secondary control restores the frequency in about one cycle, that is, $20 \mathrm{~ms}$, as it can be seen in Figure 20. During load addition and load shedding, the mean average voltage of the rms values at the PCC is modified but never falls outside the limits, because of the rapid response of the secondary control (Figure 20).

\section{Conclusions}

The droop controller for parallel-connected converters utilized throughout this research work proved to be effective for autonomous network systems since they are grid-forming converters and they can maintain system's stability, and more than that, they allow for power sharing without the utilisation of internal communication. Moreover, this paper demonstrates the necessity for the proper operation of the secondary control in order to form a stiff power network that can withstand any perturbations that may happen within 


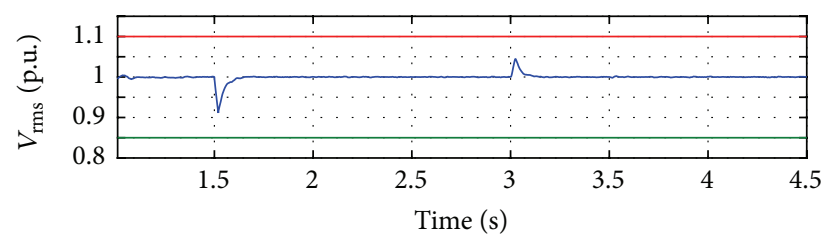

(a)

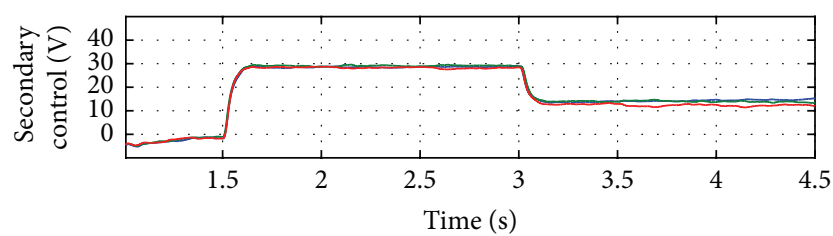

(b)

Figure 20: $V_{\text {rms }}$ values during control. (a) $V_{\text {rms }}$ at PCC. (b) Secondary control's response.

it and to ensure the system's security. At a later time, it is planned to extend the model by developing control loops to manage smartly the SOC of each storage system in order to take care of system loading and optimal power flow operation and to provide local voltage and frequency support.

\section{Conflict of Interests}

The authors declare that there is no conflict of interests regarding the publication of this paper.

\section{References}

[1] R. Lasseter, A. Akhil, C. Marnay et al., "White paper on integration of distributed energy resources: the CERTS MicroGrid Concept," Consortium for Electric Reliability Technology Solutions, California Energy Commission, 2002.

[2] J. M. Guerrero, J. Matas, L. G. de Vicuña, M. Castilla, and J. Miret, "Wireless-control strategy for parallel operation of distributed-generation inverters," IEEE Transactions on Industrial Electronics, vol. 53, no. 5, pp. 1461-1470, 2006.

[3] J. A. P. Lopes, C. L. Moreira, and A. G. Madureira, "Defining control strategies for microgrids islanded operation," IEEE Transactions on Power Systems, vol. 21, no. 2, pp. 916-924, 2006.

[4] F. Luo, Y. M. Lai, C. K. Tse, and K. H. Loo, "A triple-droop control scheme for inverter-based microgrids," in Proceedings of the 38th Annual Conference on IEEE Industrial Electronics Society (IECON '12), pp. 3368-3375, IEEE, Montreal, Canada, October 2012.

[5] J. Vasquez, J. Guerrero, J. Miret, M. Castilla, and L. Garcia de Vicuna, "Hierarchical control of intelligent microgrids," IEEE Industrial Electronics Magazine, vol. 4, no. 4, pp. 23-29, 2010.

[6] J. Rocabert, A. Luna, F. Blaabjerg, and P. Rodríguez, "Control of power converters in AC microgrids," IEEE Transactions on Power Electronics, vol. 27, no. 11, pp. 4734-4749, 2012.

[7] J. C. Vasquez, J. M. Guerrero, M. Savaghebi, J. Eloy-Garcia, and R. Teodorescu, "Modeling, analysis, and design of stationaryreference-frame droop-controlled parallel three-phase voltage source inverters," IEEE Transactions on Industrial Electronics, vol. 60, no. 4, pp. 1271-1280, 2013.

[8] G. Yajuan, W. Weiyang, G. Xiaoqiang, and G. Herong, "An improved droop controller for grid-connected voltage source inverter in microgrid," in Proceedings of the 2nd IEEE International Symposium on Power Electronics for Distributed Generation Systems (PEDG '10), pp. 823-828, IEEE, Hefei, China, June 2010.

[9] C.-T. Lee, C.-C. Chu, and P.-T. Cheng, "A new droop control method for the autonomous operation of distributed energy resource interface converters," IEEE Transactions on Power Electronics, vol. 28, no. 4, pp. 1980-1993, 2013.
[10] L.-Y. Lu, "Consensus-based P-f and Q-V droop control for multiple parallel-connected inverters in lossy networks," in Proceedings of the IEEE 22nd International Symposium on Industrial Electronics (ISIE '13), pp. 1-6, Taipei, Taiwan, May 2013.

[11] UNESA: Spanish Association for the Electrical Industry, http:// www.ree.es/sites/default/files/01_ACTIVIDADES/Documentos/ ProcedimientosOperacion/PO_resol_30jul1998_b.pdf.

[12] Union Fenosa: Spanish Electric Distribution Utility, http://www .unionfenosadistribucion.com/servlet/ficheros/1297135231943/ 1008_843_ES.0102.ES.RE.EICEd.4080911GENERADORESBT,0 .pdf. 


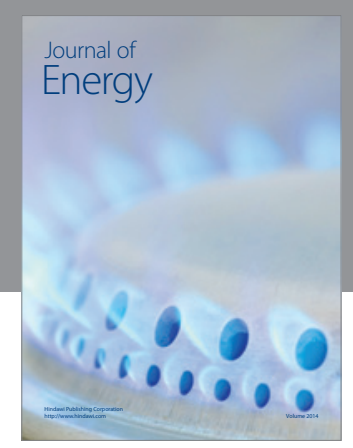

Journal of

Industrial Engineering
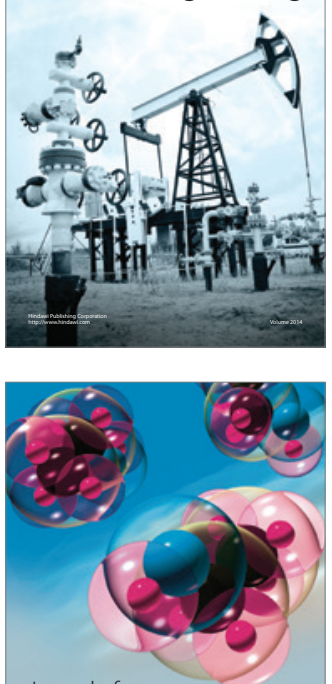

Fuels
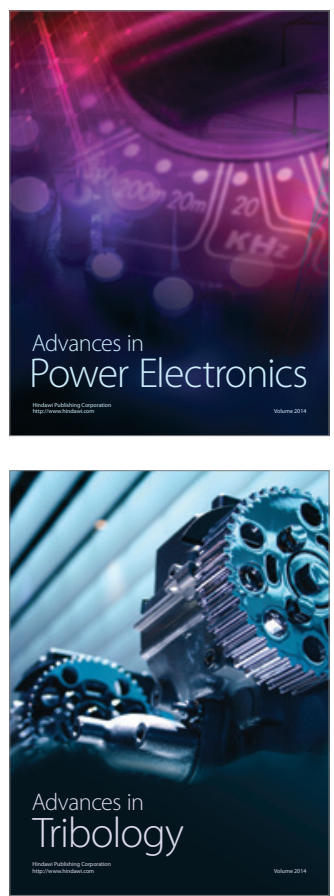

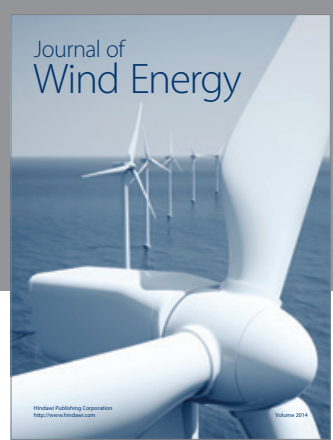

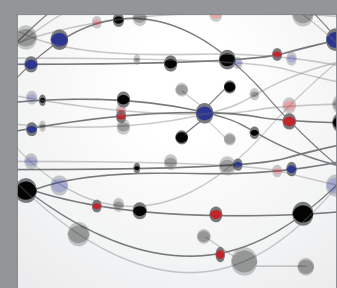

The Scientific World Journal

Submit your manuscripts at http://www.hindawi.com

Journal of

Structures
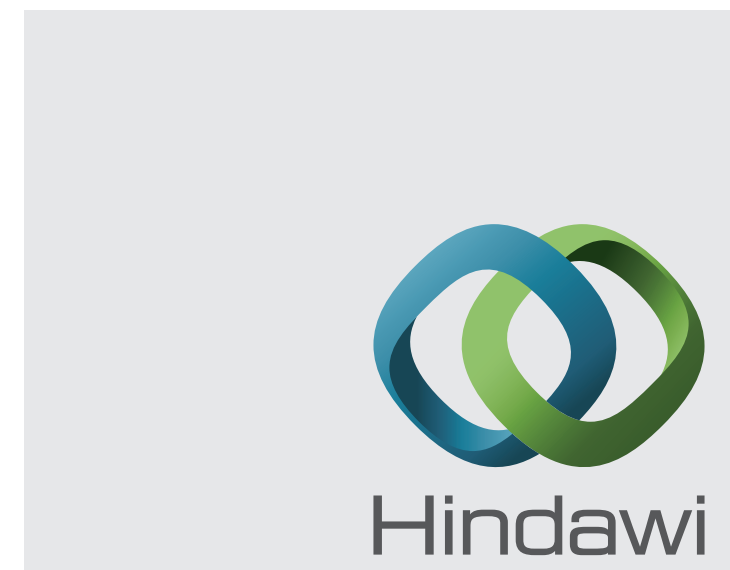

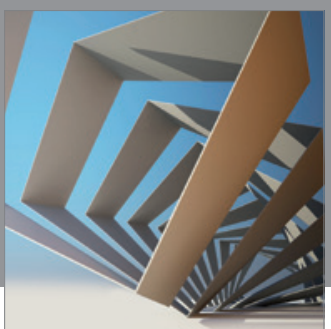

Rotating

Machinery
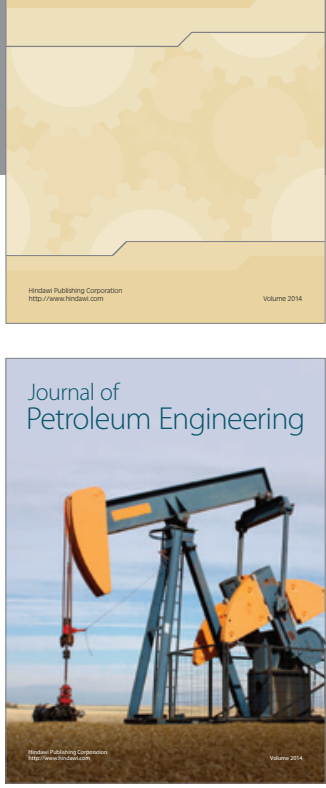

Journal of

Solar Energy
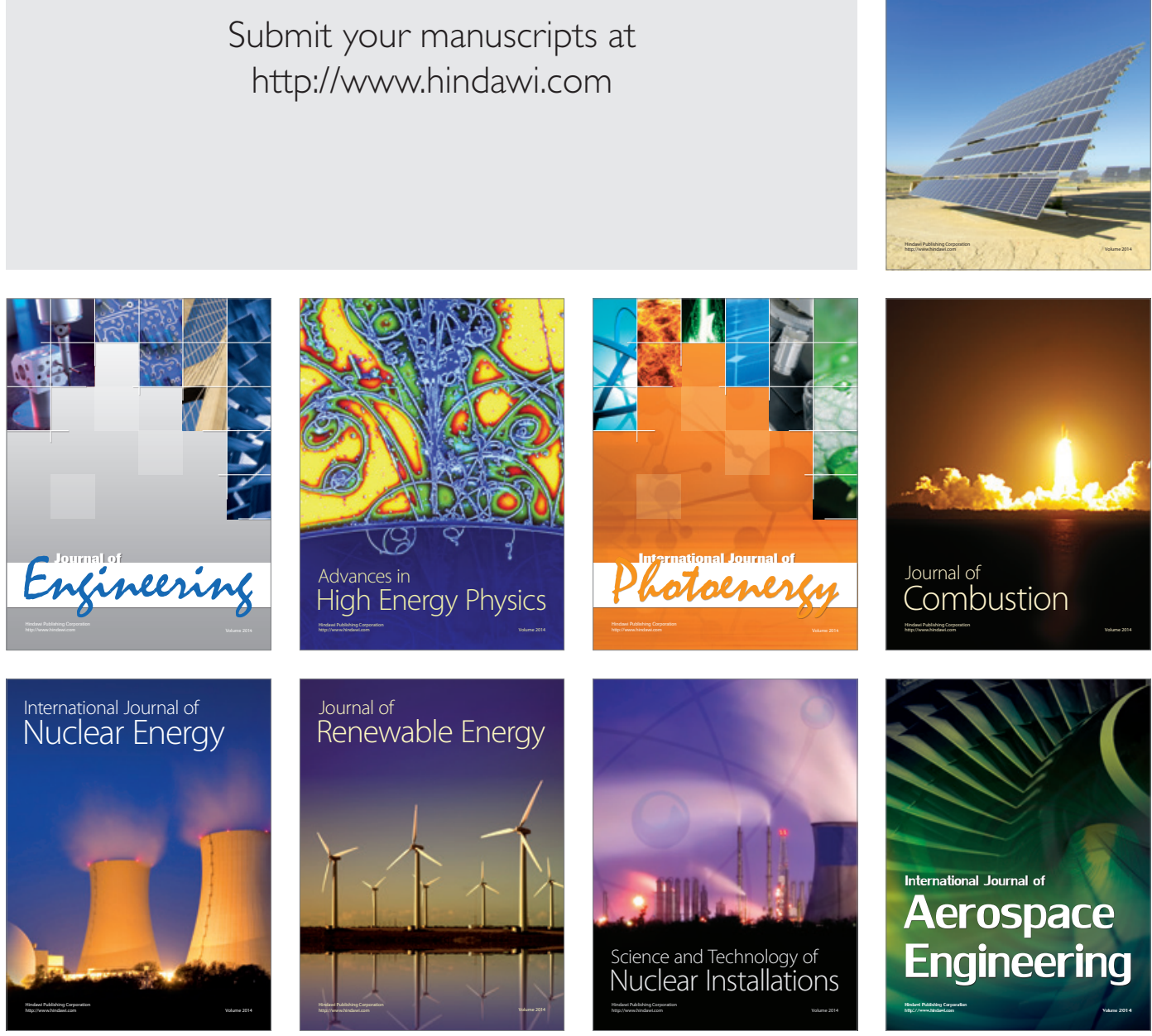